\title{
Motion for a product to collect a sample of human stool and/or urine KITLAB
}

\author{
Cláudio Márcio Bizantino de Melo ${ }^{1}$, Jandecy Cabral Leite ${ }^{2}$ \\ marciomelomanaus@hotmail.com, jandecy.cabral@itegam.org.br \\ ${ }^{1}$ Centro Universitário do Norte (UNINORTE). AV. Joaquim Nabuco, 1469, Centro. Manaus - Amazonas - Brasil. CEP: 69005- \\ 290. Fone: +55 (92) 32155000 . \\ ${ }^{2}$ Instituto de Tecnologia e Educação Galileo da Amazônia (ITEGAM). Avenida Joaquim Nabuco, 1469, Centro. Manaus - \\ Amazonas - Brasil. CEP: 69020-031. Fone: +55 (92) 3584 6145/ +55 (92) 32482646.
}

\begin{abstract}
A marketing innovation is the key factor of any product to be launched in the consumer market. This research anticipates that had already been patented worldwide launch of a product (non- chemical) pharmaceutical industry to be called KITLAB, which will change for the better the procedure and user form to collect a single sample of feces or urine be taken for laboratory examination. The objective of this paper is to show product innovation to make a collection of these hygienically correct. The methods and techniques are their main advantages it has over its competitors, since it enables the user to make a collection without handling, that is, that a sample collection (feces/urine), is made by everyone (men/women, adults/children) hygienically, in a very different way of unhygienic today make such collections, which are, at best, made directly on the floor without any care with possible contamination toilet that such unsuitable sites can provide samples. The results observed in a study commissioned assessment of market viability showed that the product had total public approval, and in addition, he has numerous competitive advantages over other existing competing products in the market because its use eliminates the so inconvenient, self - embarrassing and unhygienic way of making today a collection of stools, and more, it will give the user a personal satisfaction and comfort, finally, this product will eliminate the so uncomfortable handling necessary that still exists today.
\end{abstract}

Keywords: fecal coliforms, Waste Health Services, Feces, urine, secretions and organic liquids, Remains of laboratory samples and their containers.

\section{Propuesta de un producto para recoger una muestra de materia fecal humana y/o KITLAB orina.}

\section{RESUMEN}

Una innovación de comercialización es el factor clave de cualquier producto que se lanzará en el mercado de consumo. Esta investigación anticipa el lanzamiento mundial de un producto (no químico) de la industria farmacéutica, patentado, llamado KITLAB, que va a cambiar para mejor el procedimiento y formulario de usuario para recoger una sola muestra de heces que deben adoptarse para su examen en laboratorio, hoy en día, en todo el mundo, se pone fuera de la taza del baño. El propósito de este artículo es mostrar que este producto permite al usuario (hombre / mujer, adulto / niño) a una colección de material de examen de la muestra en un ambiente higiénicamente correcta, es decir, dentro del propio inodoro y sin ningún tipo de manipulación, muy diferente la forma antihigiénica hoy para hacer ese tipo de colecciones, que son, en el mejor, hace directamente en el suelo sin ningún cuidado con la posible contaminación que dichos sitios pueden proporcionar muestras recolectadas no aptos. En la investigación, se comparó la funcionalidad de este producto con los ya existentes, y el resultado fue favorable a él por completo, ya que su uso elimina la forma tan inconveniente, sí embarazoso y poco higiénicas de hacer hoy una colección de sillas, y mucho más, se le dará al usuario una satisfacción personal y el confort, por último, este producto se eliminará la tan incómodo manejo necesario que todavía existe hoy.

Palabras clave: Coliformes fecales, Servicios de Residuos, heces, orina, secreciones y fluidos corporales, muestras de laboratorio sobrantes y sus contenedores. 
Cláudio Márcio Bizantino de Melo \& Jandecy Cabral Leite/ ITEGAM-JETIA Vol.01, Nº 02, pp.38-44. Junho, 2015.

\section{INTRODUÇÃO}

A presente proposta de modificação da maneira de se coletar uma amostra humana de fezes e/ou de urina para ser levada a laboratório para exame trata-se de um penico desmontável para se coletar amostras de fezes e urina para exame de laboratório, idealizado para ser usado dentro de qualquer vaso sanitário, pois possui longas abas para se apoiar e se fixar sobre as bordas de qualquer vaso sanitário e uma cuba que pode ser separada do seu corpo, a fim de permitir que essa cuba se transforme no recipiente coletor que tem de ser levado a laboratório para exame.

Justifica-se esta proposta porque ela é a única que atende as recomendações médico/farmacêuticas quanto á higiene duma coleta: As fezes devem ser colhidas em recipientes fornecidos pelo laboratório ou em frascos bem limpos e secos com tampas. A amostra não pode estar contaminada com urina ou água. Não é necessário um volume de fezes maior do que $3 / 4$ do frasco [1].

Esse produto visa possibilitar que o usuário faça uma coleta de fezes sem manuseio nenhum. $\mathrm{O}$ fato desse produto ser desmontável vai possibilitar que o usuário nunca mais faça uma coleta de fezes fora de um vaso sanitário, isto é, de agora em diante toda coleta de fezes para ser levada a laboratório vai poder ser feita dentro de qualquer vaso sanitário, com a mais perfeita higiene e comodidade nunca dantes imaginadas.

As funções da limpeza são várias, tendo em conta duas vertentes: a vertente microbiológica, já que através dela são removidos os micro-organismos do ambiente, pela remoção da sujidade, tornando as superfícies seguras para doentes e profissionais, e a vertente não microbiológica que consiste em manter a aparência [2].

Devido a cuba desse produto vir também a ser o recipiente coletor a ser levado a laboratório para exame, que tem uma capacidade total de volume de $160 \mathrm{ml}$, isso fará com que essa operação tenha uma adequada e ideal higienização do ambiente onde a coleta do material a ser levado a exame será feita, ou melhor, a cuba desse produto será o ambiente higienicamente preparado para receber qualquer coleta de material, seja de fezes ou de urina, e mais, essa singular capacidade e funcionalidade vai evitar o tão inconveniente e constrangedor manuseio usuário da amostra que essa operação hoje nos causa.

\section{REVISÃO BIBLIOGRÁFICA}

A partir da segunda metade do século XX, com os novos padrões de consumo da sociedade industrial, a produção de resíduos vem crescendo continuamente em ritmo superior à capacidade de absorção da natureza. Nos últimos 10 anos, a população brasileira cresceu $16,8 \%$, enquanto que a geração de resíduos cresceu $48 \%$ [3].

Dentre as políticas nacionais e legislações ambientais existentes que contemplam a questão de resíduos sólidos, destacam-se aquelas que dispõem sobre: a Política Nacional de Meio Ambiente (Lei no 6.938 de 31/08/1981), a Política Nacional de Saúde (Lei Orgânica da Saúde no 3.080 de 19/09/90), a Política Nacional de Educação Ambiental (Lei nº 9. 795 de
27/04/1994), a Política Nacional de Recursos Hídricos (Lei ${ }^{\circ}$ 9.433 de 08/01/1997), a Lei de Crimes Ambientais (Lei no 9.605 de 12/02/1998), o Estatuto das Cidades (Lei $n^{\mathbf{o}} 10.257$ de10/07/2001); a Política Nacional de Saneamento Básico (Projeto de Lei $n^{\circ}$ 5.296/05) e a Política Nacional de Resíduos Sólidos (projeto de lei), sendo que esses dois últimos encontramse em apreciação junto ao Congresso Nacional [4].

Pouco, quase nada, se tem falado (escrito) a respeito de qual seria o mais adequado local físico (se direto no chão dos banheiros, ou sobre quaisquer papéis ou jornais) onde o material a ser coletado para um exame de fezes deve ser defecado pelo paciente, antes dele o transportar para o copo coletor a ser levado a laboratório para exame.

Encontraram-se orientações para coleta em laboratório particular pouco direcionada como esta: (Coleta do parasitológico de fezes) - Evacuar em local bem limpo e seco. Absolutamente contraindicada à coleta na água do vaso sanitário. Admite-se a coleta sobre a fralda descartável nova [5].

Com relação à Política Nacional de Resíduos Sólidos, as primeiras iniciativas legislativas para a definição de diretrizes à área de resíduos sólidos surgiram no final da década de 80 . Desde então, a questão de resíduos sólidos vem sendo exercida pela atuação dos órgãos regulatórios, por meios de resoluções do Conselho Nacional de Meio Ambiente - CONAMA e da Agência Nacional de Vigilância Sanitária - ANVISA, no caso de resíduos do serviço de saúde (RSS) [4].

Há, porém, o plano de gerenciamento de resíduos de serviços de saúde (PGRSS), que é um documento que aponta e descreve as ações necessárias ao manejo de resíduos de infecções gerados pelos pacientes nas instituições de saúde, como hospitais e prontos-socorros.

No entanto, mesmo que as instituições de saúde tenham um planejamento de como se evitar contaminações hospitalares, geradas por resíduos de serviços de saúde (excreções, secreções e líquidos orgânicos), pois esse é o objetivo desse plano, não há nenhuma observação médica ou laboratorial que determine o local onde os pacientes devem fazer as coletas de fezes, por isso, os pacientes ficam inteiramente desorientados e ao mesmo tempo livres de escolherem se fazem a defecação no chão do banheiro ou mesmo dentro da contaminada água do vaso sanitário.

De acordo com alguns estudos feitos, a higienização das superfícies seguindo a metodologia correta e aplicando água quente e detergente, consegue remover $80-85 \%$ dos microorganismos presentes. Se for aplicado desinfetante após a limpeza, pode-se remover cerca de 90-95\% destes microorganismos. No entanto o tempo que leva uma superfície a voltar a estar contaminada é o mesmo quer se tenha aplicado ou não desinfetante. Partindo desse pressuposto, não se pode considerar que esta prática seja custo-efetiva além de que a aplicação indiscriminada de desinfetantes gera outros problemas de poluição ambiental de importância acrescida para o equilíbrio do ambiente e saúde das populações [2].

Os banheiros de qualquer instituição de saúde são sempre de uso coletivo, seja diário ou não, quer dizer, os resíduos de fezes deixados num banheiro por um paciente, sejam resíduos 
infecciosos ou não, estão sempre passiveis de contaminar outro paciente que precise e que tem de usar esse mesmo banheiro.

Nem sempre, depois que um paciente termina de fazer a sua coleta de fezes para exame, dá tempo que os encarregados da desinfecção façam a limpeza dos banheiros antes de lá entrar outro paciente, quer dizer, o perigo de haver uma contaminação, depois que um paciente faz uma defecação para uma coleta de amostra para um exame de fezes, sempre existe.

A metodologia da limpeza e os produtos empregues na mesma são sempre iguais para qualquer área do hospital, quer estas sejam consideradas ou não, de risco. O que varia é a frequência de limpeza necessária e instituída para cada área, consoante a especificidade dos serviços e susceptibilidade dos doentes [2].

Mesmo que os órgãos de serviços de saúde zelem pela total e ampla higiene de suas dependências (recepção, corredores, apartamentos, enfermarias e banheiros, etc.), não existe, em nenhum plano desses, uma atenção voltada especificamente parao local físico (banheiro) onde os pacientes geram seus próprios resíduos fecais (sólidos ou não), resíduos esses que são, muitas vezes, altamente passíveis de geral contaminação.

\subsection{CLASSIFICAÇÃO DOS RSS (RESÍDUOS DE SERVIÇOS DE SAÚDE)}

Resíduos de serviços de saúde são os corpos físicos, sólidos ou não, que apresentam uma possível presença de agentes biológicos que, por suas características de maior virulência ou concentração, podem apresentar risco de infecção.

Os resíduos discriminados abaixo representam os classificados como sendo do grupo A, pois apresentam risco devido à presença de agentes biológicos [4].

GRUPO A: Sangue e hemoderivados; Excreções, secreções e líquidos orgânicos; Meios de cultura; Tecidos, órgãos, fetos e peças anatômicas; Filtros de gases aspirados de áreas contaminadas; Resíduos advindos de área de isolamento; Resíduos alimentares de área de isolamento; Resíduos de laboratório de análises clínicas; Resíduos de unidade de atendimento ambiental; Resíduos de sanitário de unidades de internação; Objetos perfuro-cortantes provenientes de estabelecimentos prestadores de serviços de saúde.

Os estabelecimentos de saúde devem ter sempre um responsável técnico, devidamente registrado em conselho profissional, para o gerenciamento de seus resíduos. Os restos de resíduos sólidos do grupo A devem ser acondicionados em sacos plásticos grossos, brancos, leitosos e resistentes, com simbologia de substância infectante, antes de serem incinerados, porém, para os restos de resíduos de fezes deixados nos banheiros pelos pacientes depois de uma coleta dessas não há tanta preocupação, porém, o risco do início de uma possível contaminação geral por tais resíduos é igual ou maior que dos outros resíduos.

\section{MATERIAIS E MÉTODOS \\ 3.1 Matéria-prima}

A matéria-prima escolhida para a confecção e fabricação da base de sustentação desse produto foi o polipropileno (PP), devido esse material ser o mais apropriado durantes os ensaios de resistência de peso (para a base de sustentação) e também para os ensaios de estanqueidade da sua cuba central (copo coletor). Além do polipropileno, o poliestireno (PE) também foi ensaiado, no entanto, nos ensaios, o polipropileno se mostrou ser a matériaprima mais adequada para a fabricação desse produto como mostra a figura 1 .

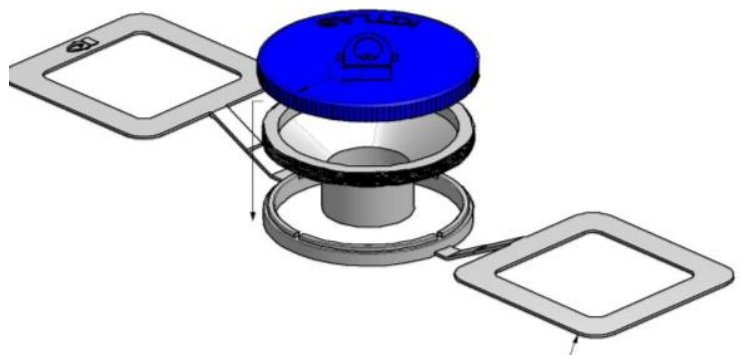

Figura 1. KITLAB.

\subsection{FORMA DE INSTALAÇÃO}

A forma de se instalar o $\boldsymbol{K I T L A B}$ num vaso sanitário é tão simples que até mesmo uma criança é capaz de fazê-la, afinal, basta levantar-se a tampa e o assento do vaso, colocar sobre as suas bordas a base sanitária, desdobrada, já com o copo coletor instalado, e abaixar o assento, para lhe dar a fixação da posição escolhida, que estará completada a sua instalação, conforme mostra a figura 2 .
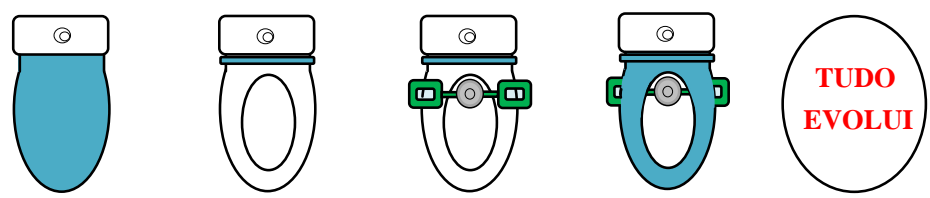

Figura 2. Como instalar o KITLAB.

\section{RESULTADOS E DISCUSSÕES}

\subsection{Proposta da Inovação - Estudo de Caso}

Como estratégia de pesquisa, utiliza-se o estudo de caso em muitas situações, para contribuir com o conhecimento que temos dos fenômenos individuais, organizacionais, sociais, políticos e de grupo, além de outros fenômenos relacionados. De forma não surpreendente, o estudo de caso tem se constituído uma estratégia comum de pesquisa na psicologia, sociologia, ciência política, trabalho social.

Em geral, os estudos de caso representam a estratégia preferida quando se colocam questões do tipo "como" e "por que", quando o pesquisador tem pouco controle sobre os acontecimentos e quando o foco se encontra em fenômenos contemporâneos inseridos em algum contexto da vida real [6].

A presente novidade mercadológica trata-se de um aparelho de plástico (polipropileno), constituído de 4 (quatro) peças distintas (base, cuba central (copo coletor), tampa e pá) dobrável, projetado especificamente para, depois de desdobrado, ser colocado e apoiado firme e fixamente sobre as bordas laterais de um vaso sanitário, e que tem por objetivo facilitar uma coleta 
pessoal de amostra para ser levada a exame laboratorial, seja o exame de fezes ou de urina.

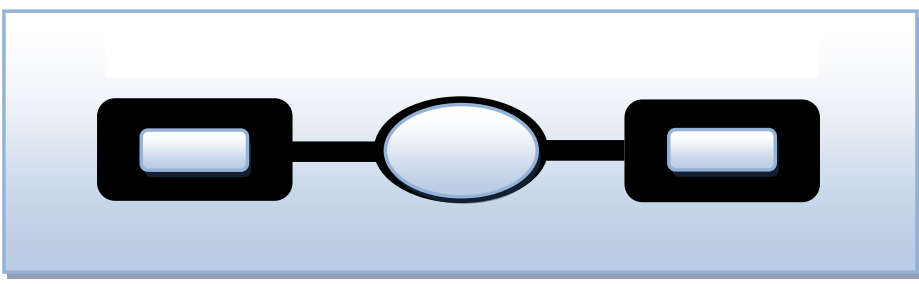

Figura 3. Mostra o KITLAB fora do vaso, desdobrado, sem a sua cuba central.

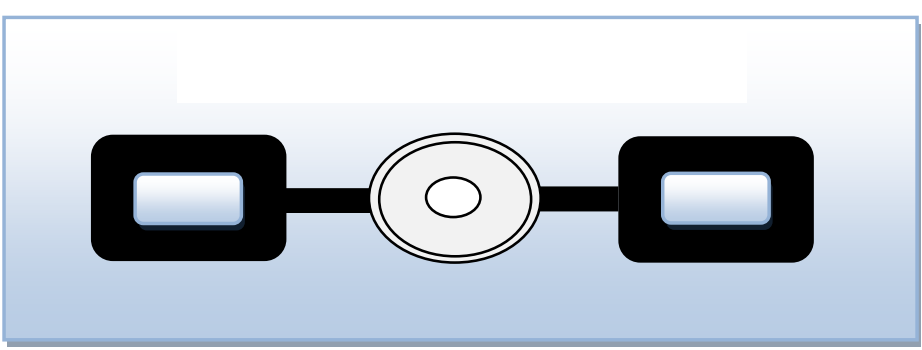

Figura 4. Mostra o KITLAB fora do vaso, desdobrado, com a sua cuba central.

Esse aparelho funciona como se fosse um "penico" para ser usado dentro de um vaso sanitário, no entanto, a sua cuba central (copo coletor) foi propositalmente projetada para ser desmontável do seu corpo, a fim dela mesmo poder ser levada a laboratório para exame, e a base de sustentação do KITLAB, que é o seu corpo, depois de desdobrado, fica com longas abas laterais que podem se apoiar sobre as bordas do vaso, e ainda podem suportar um peso de até $600 \mathrm{~g}$ de amostra, como mostra as figuras 5 e 6.

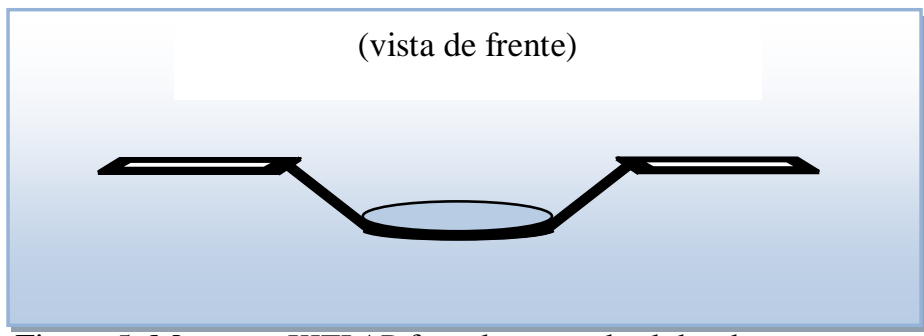

Figura 5. Mostra o KITLAB fora do vaso, desdobrado, sem a sua cuba central.

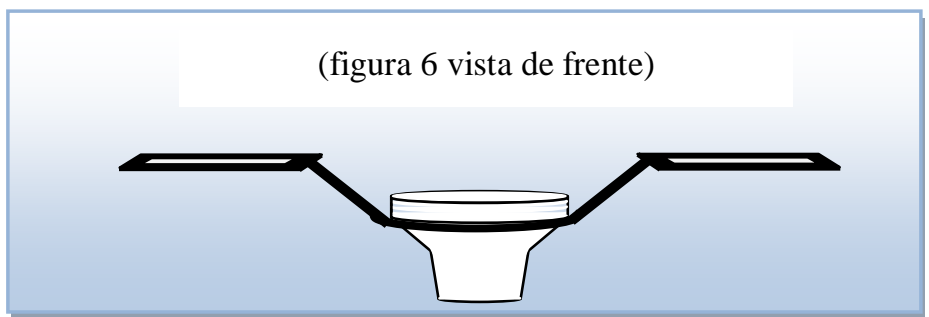

Figura 6. Mostra o KITLAB fora do vaso, desdobrado, com a sua cuba central.
Esse produto, quando está com as suas abas laterais dobradas, tem, praticamente, as mesmas dimensões da sua cuba central (copo coletor), e isso foi projetado assim para se diminuir o volume linear do seu corpo e facilitar tanto a logística de transporte como o seu transporte usuário como mostra a figura 7.

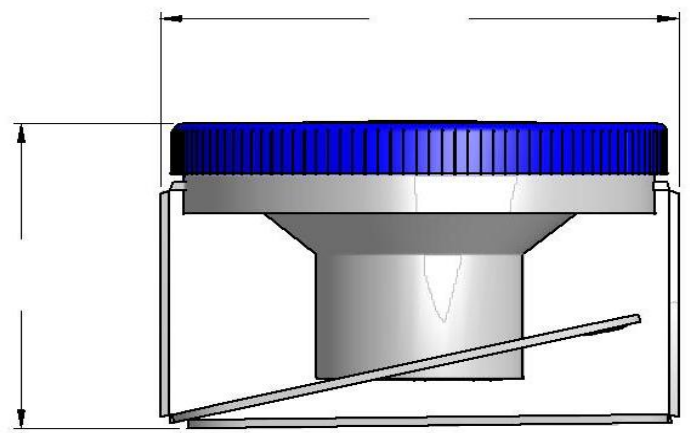

Figura 7. KITLAB quando sai da embalagem.

A cuba central (copo coletor) desse aparelho facilitador de coleta de amostra de fezes (ou de urina) possui uma tampa roscável que foi propositalmente projetada para ter um fechamento completamente hermético, isto é, não vaza, nem quando posto de lado (deitado) nem quando de cabeça para baixo, e, além disso, a boca dessa cuba tem um diâmetro que é, no mínimo, o dobro do diâmetro das bocas de qualquer dos atuais aparelhos (copos coletores) afins.

E mais, devido essa cuba ser desmontável, ele mesmo se transforma no recipiente coletor a ser levado pelo usuário a laboratório para exame, enfim, visto que a coleta pode ser feita (dentro do vaso sanitário) diretamente no dispositivo a ser levado a laboratório, faz essa "operação" ser uma coleta sem manuseio. A capacidade total de volume dessa nova cuba (copo coletor) é de $160 \mathrm{ml}$ (cone menor + cone maior), porém, a quantidade necessária de amostra (fezes/urina) para um laboratório fazer um exame gira em torno de, no máximo, $50 \mathrm{ml}$, que é o volume do seu cone menor.

\section{Cuba central}

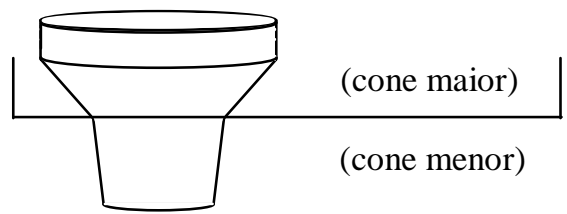

Figura 8. Diferença entre os cones.

\subsection{PESQUISA DE OPINIÃO PÚBLICA}

Nessa pesquisa, que foi feita em duas etapas, várias perguntas foram feitas aos entrevistados, porém, apresentaremos aqui somente algumas dessas respostas. Na primeira etapa da 
pesquisa, os entrevistados responderam as perguntas sem ainda terem nenhum conhecimento desse novo produto, no entanto, as respostas das perguntas da segunda etapa já foram respondidas tendo os entrevistados já conhecimento do novo produto, o KITLAB.

ETAPA 1 (Perguntas feitas pelos entrevistadores ANTES dos entrevistados terem tomado conhecimento da "Proposta de modificação da maneira de se coletar uma amostra humana de fezes e/ou de urina para ser levada a laboratório para exame").

A figura 9 mostra o percentual dos entrevistados quanto à maneira que deve ser um coletor de fezes.

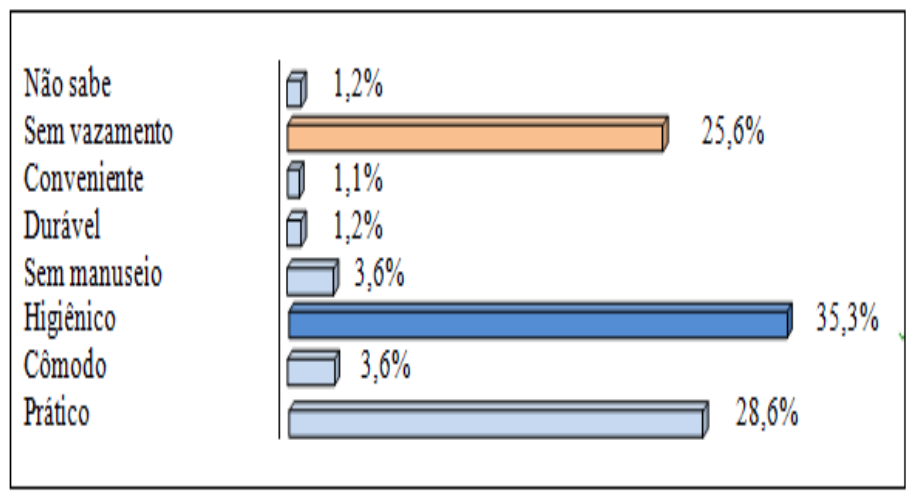

Figura 9. Percentual quanto à maneira que deve ser um coletor.

A figura 10 mostra o percentual de entrevistados segundo o principal inconveniente quando se faz uma coleta de material de fezes.

\begin{tabular}{|c|c|c|c|}
\hline \multicolumn{2}{|c|}{} & \multicolumn{2}{|c|}{ Não sabe } \\
\hline $\begin{array}{c}\text { Uso do vaso sanitário } \\
\text { Não há inconveniente } \\
\text { ao se usar o vaso } \\
\text { sanitário, mas sim } \\
\text { quando se vai retirar } \\
\text { o material coletado } \\
\text { no vaso para dentro } \\
\text { do copo coletor }\end{array}$ & $\begin{array}{c}\text { Oaso inconvenionte é } \\
\text { duplo: Não usar o } \\
\text { ter de colocar a } \\
\text { amostra para dentro } \\
\text { do copo coletor }\end{array}$ & $\begin{array}{c}\text { Essa classe prefere } \\
\text { coletar a amostra } \\
\text { diretamente para o } \\
\text { copo coletor }\end{array}$ \\
\hline
\end{tabular}

Figura 10. Percentual segundo o principal inconveniente quando se faz uma coleta de material de fazes.

ETAPA 2 (Perguntas feitas pelos entrevistadores DEPOIS dos entrevistados terem tomado conhecimento da "proposta de modificação da maneira de se coletar uma amostra humana de fezes e/ou de urina para ser levada a laboratório para exame"). A figura 11 mostra o percentual de entrevistados quando perguntado qual produto é o mais prático.

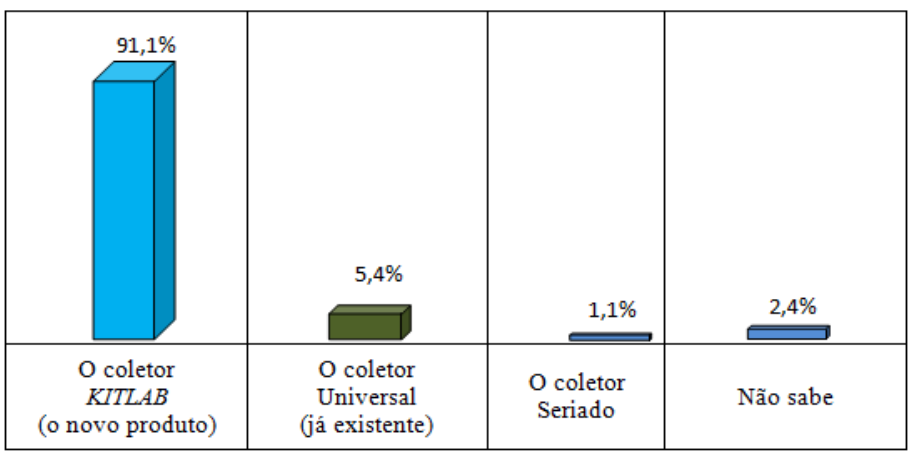

Figura 11. Percentual em relação ao produto mais prático.

A figura 12 mostra o percentual de entrevistados quanto à avaliação do produto com nota de 1 a 10 .

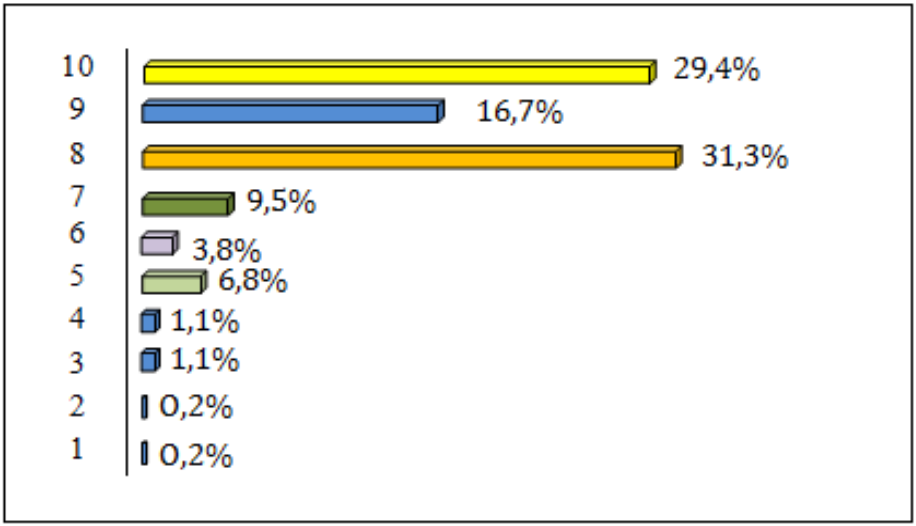

Figura 12. Percentual com avaliação de nota de 1 a 10.

\subsection{INOVAÇÃO DO PRODUTO}

O que o mercado consumidor oferece hoje para a realização de um exame laboratorial (fezes/urina) é apenas um copo coletor, de plástico, com capacidade de volume de, no máximo, $80 \mathrm{ml}$, onde a amostra do material do exame, feita em locais não-higienizados, deve ser colocada com a ajuda de uma pequena pá, de, no máximo 4 (quatro) centímetros de comprimento, que acompanha esse copo. A forma de hoje se coletar nas residências uma amostra de material a ser levado a exame é feita em cima de folhas de quaisquer papéis ou jornais, ou sobe quaisquer outros objetos, ou mesmo diretamente no chão, ou sobre a contaminada água do vaso sanitário, que, geralmente tem uso coletivo, familiar ou não, sem que ninguém, nem a classe médica nem a laboratorial nem a usuária tenha a menor preocupação com uma possível contaminação da amostra por germes existentes nesses impróprios, não esterilizados e antihigiênicos locais de coleta.

A pá que acompanha o copo coletor que hoje é vendido no mercado, apesar de ser rígida para o que ela se propõe a fazer, é muito pequena, e por ser tão pequena, faz a sua imprescindível utilização ser um ato passível de constrangimento íntimo, devido ao possível acidental contato usuário das mãos com o material da amostra. 
A estratégia de lançamento de produtos inovadores é vista como a estratégia de lançamento de sucesso para os produtos inovadores com alta tecnologia [7][8][9[10]. Isto tem um melhor aproveitamento do produto de estratégias alternativas ao introduzir produtos alinhados com decisões táticas tais como preços de desnatação e nova marca ou canais [11][12][13]. Além disso, a estratégia de lançamento de produtos inovadores tem como objetivo principal para atingir diversos segmentos específicos de clientes, cujas necessidades podem não ser suficientemente satisfeito pelos concorrentes maiores [14[15], ou cujos números de concorrente são poucos [16].

\subsection{Modo de usar}

Abra as hastes e encaixe o recipiente no suporte como mostra a figura 13. Encaixe e posicione o suporte na borda do vaso sanitário como mostra a figura 14.

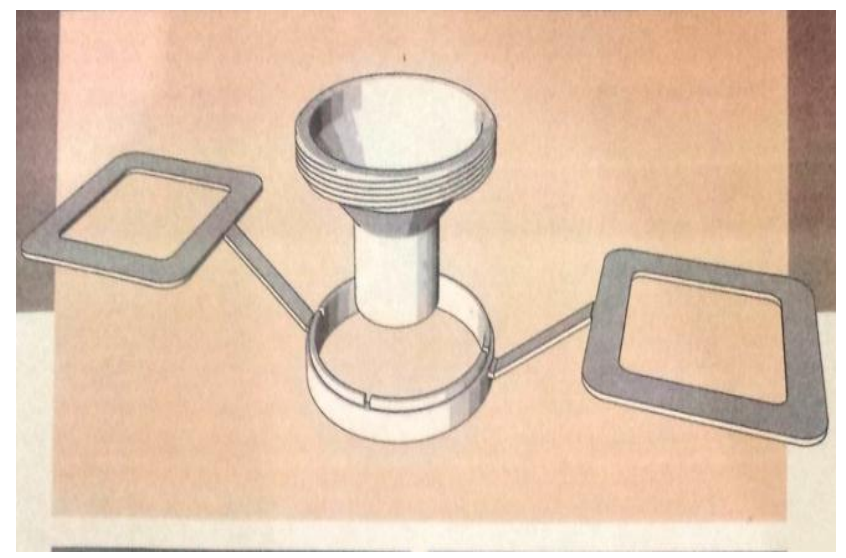

Figura 13. Haste e encaixe do suporte.

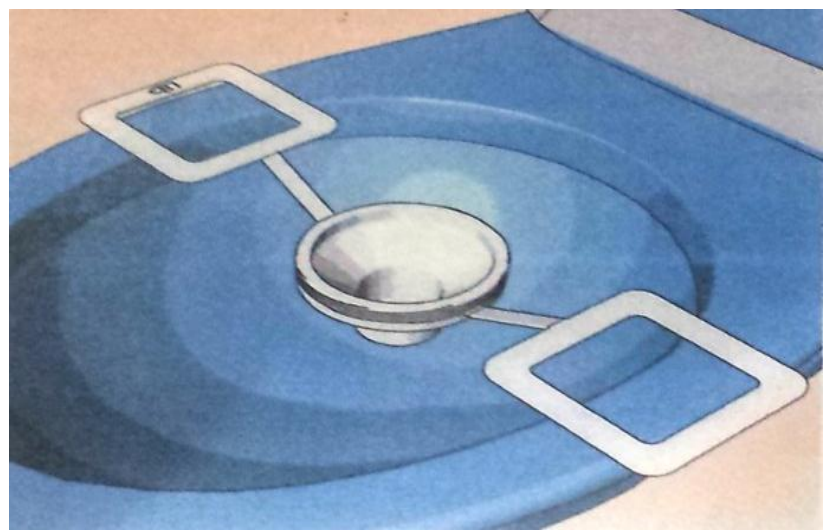

Figura 14. Encaixe e posicione o suporte na borda do vaso sanitário.

A Trave o suporte com o assento do sanitário. O Kitlab está pronto para ser usado como mostra a figura 15 . O Recipiente possui abertura maior do que os recipientes no mercado. Facilitando a coleta do resíduo. A haste evita o constrangimento e o contato direto. Retire o recipiente já com o resíduo e feche a tampa do kit. Como mostra a figura 16.

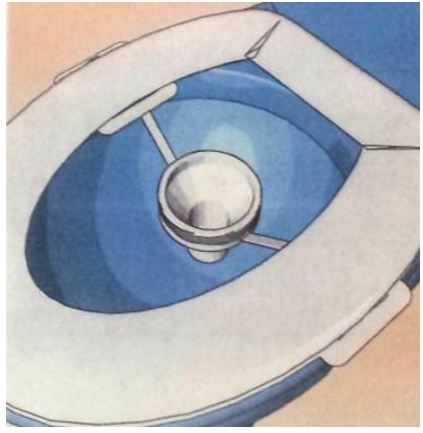

Figura 15. Pronto pra usar.

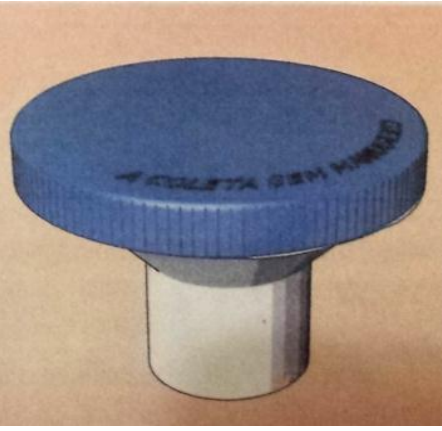

Figura 16. pronto para ser levado ao laboratório.

\section{Conclusões}

A própria classe médica, que já tomou prévio conhecimento desse novo produto, devido ao inusitado, higiênico, facilitador, providente e usualmente prático surgimento dessa nova e higiênica forma de coleta, se sentirá induzida a recomendar que, doravante, tais exames só poderão ter a sua aprovação se realizados conforme as condições de higiene que esse produto virá a oferecer.

A classe laboratorial também se sentirá mais confiante na divulgação do resultado de um exame desses, sabendo que a classe usuária seguiu a higiênica forma de se fazer a coleta recomendada pela classe médica. A classe usuária também, principalmente ela, certamente, além de vir a aplaudir conjuntamente com as classes médica e laboratorial a solução higiênica para a realização de um exame desses, se sentirá automotivada e também induzida a só se submeter a um desses exames mediante a utilização da funcionalidade desse novo produto, quer dizer, em pouco tempo, já não será possível que um exame desses ainda venha a ser realizado $\mathrm{n}$ os moldes dos atuais, sem quaisquer cuidados higiênicos.

Muitos, principalmente homens, não verão a necessidade de se utilizar o KITLAB para se fazer uma coleta de urina dentro de um vaso sanitário, pois acharão que essa tarefa pode ser feita direta na sua cuba, e fora do vaso, porém, quando uma criança é submetida a fazer esse exame é que se vê que o que para um adulto pode ser simples, para uma criança não é, principalmente se essa criança for uma menina.

AGRADECIMENTOS: Ao Centro Universitário do Norte (UNINORTE), pelo apoio a realização desta pesquisa.

\section{Referências Bibliográficas}

[1] http://www.labivida.com.br/web/info_coleta_fezes (Acesso em 15 de Março 2014). 
[2] Manual de Gerenciamento de Resíduos de Serviços de Saúde/ Ministério da Saúde. Agência Nacional de Vigilância Sanitária. Brasília: Ministério da Saúde, 2006.

[3] IBGE. Instituto Brasileiro de Geografia e Estática. 2000. Disponível em: <http://www.ibge.gov.br> Acesso em 30 Abril 2014.

[4] ANVISA. Manual de gerenciamento de resíduos de serviços de saúde/Ministério da Saúde, Agência Nacional de Vigilância Sanitária. Brasília: Ministério da Saúde, 2006, p. 9 36.

[5] http://www.laboratoriolapec.com.br/index.php?tion=com content $\&$ view $=$ article $\&$ id $=50 \&$ Itemid $=55 \# 7$ (Acesso em 30 de Abril 2014).

[6] Yin, Robert K. Estudo de Caso: Planejamentos e Métodos $3^{\mathrm{a}}$ edição - porto alegre: Bookman, 2010.

[7] Archer, Elizabeth et al. Procedimentos e protocolos. Rio de Janeiro: Guanabara Koogan, 2005.

[8] Ayliffe, G.A.J.; Lowbury, E.J.L.;Geddes, A.M. e Williams, J. Control of Hospital Infections. $3^{\mathrm{a}}$ Edição, Chapman \& Hall Medical, capítulo 6, pp, 78-112; (2002).

[9] Ayliffe, G.A.J.; Collins, B.J.; Taylor, L.D., Hospital Acquired Infection, Principles and preventions. Hospital Environment, cap. 8. pp: 71. (2002).

[10] Carmagnani, M. I.S. et al. Procedimentos de enfermagem: guia prático. Rio de janeiro: Guanabara Koogan, 2009.

[11] MANUAL de procedimentos de enfermagem. São Paulo, 2005. Disponível em: <http://www.unifesp.br/spdm/manual_hosp/arquivos/manuais/>. Acesso em: 6 out. 2009.

[12] Ministério da Saúde. Saúde ambiental e gestão de resíduos de serviços de saúde. Projeto Reforsus. Brasília: Ministério da Saúde, 2003.

[13] Schneider, Vania Elisabete (org.). Manual de Gerenciamento de Resíduos Sólidos de Saúde. Caxias de Sul (RS). Editora da Universidade de Caxias do Sul - EDUCS. 2a . ed. rev. e ampl., 2004.

[14] Weber, J. David M.D.,M.H.P., Rutala, William, Ph. D., M.P.H., Prevention and control of Nosocomial Infections. Environmental issues", 2a Edição, cap. 19, p. 420. 2002.

[15]www.camara.gov.br/internet/diretoria/Conleg/notas/0103 1.pdf (Tratamento de Resíduos Sólidos - Ilidia Juras)

[16]http://www.ambientebrasil.com.br/composer.php3?base./ educacao/index.php3\&conteudo=./educacao/programas/integraca o21.html. 